\title{
ASSERTING AGENCY: NAVIGATING TIME AND SPACE FOR TEACHING DEVELOPMENT
}

\section{J. Jawitz*}

Centre for Higher Education Development

e-mail: jeff.jawitz@uct.ac.za

\section{T. Perez*}

Sociology Department

e-mail: tpz031@googlemail.com

*University of Cape Town

Cape Town, South Africa

\section{ABSTRACT}

Within research-intensive institutions, a dominant research discourse constrains academics' engagement with professional development opportunities for teaching. This study shows how academics at the University of Cape Town overcome these constraints through asserting agency. An analysis of their narratives reveals how an ability to navigate time and engagement with the professional development space is informed by alternative approaches, which we have labelled as pragmatic, social and reflexive. Each approach provides a different basis for justifying engagement with professional development opportunities for teaching in terms of the functions that these opportunities can fulfil. We argue that this set of justifications reflects academic agency in action and serves to lessen the power of the dominant research discourse. In so doing, they also undermine their colleagues' forms of rationalisation for locating teaching as secondary within the institution.

Keywords: teaching development, institutional culture, professional development, researchintensive

\section{INTRODUCTION}

The culture of research dominance in higher education has been well documented with regard to the impact on academics’ role as teachers (Leisyte, Enders and De Boer 2009; Kreber 2000; Chalmers 2011; Leibowitz, Van Schalkwyk, Ruiters, Farmer and Adendorff 2012), how academics spend their time (Colbeck 1998) and their engagement with professional development (Leibowitz, Bozalek, Van Schalkwyk and Winberg 2015; Van Schalkwyk, Leibowitz, Herman and Farmer 2015; Leibowitz 2014). In the context of South African research intensive institutions: 
... teaching often resides both structurally and culturally in a contested and unequal space which sees research being regarded as the coin of the realm. In our study, despite many positive comments about how people felt about their teaching, we were not surprised to find that the privileging of research was seen as a dominant discourse (Van Schalkwyk et al. 2015, 3).

A dominant research discourse has led to a widespread assumption in research-intensive institutions that teaching takes time away from research and therefore engagement in professional development (PD hereafter) for teaching may have an adverse effect on career prospects. This article contributes to a body of literature concerned with understanding how academics in research-intensive institutions are able to make choices that do not assume teaching is a threat to research (Skelton 2012).

Asserting agency in this article is used to describe an ability to overcome the constraints posed by dominant research discourses. Previously, this has been discussed in relation to academics' ability to utilise PD for teaching opportunities to navigate the risks posed to academics’ research identity (Jawitz and Perez 2015). In contrast, this article focuses on how academics' explanations of asserting agency demonstrate alternative ways of thinking. These perspectives represent a departure from past routines and habits that have become entrenched by a dominant research discourse.

This article begins with an example of how dominant research discourses currently inform the culture at the University of Cape Town (UCT). This is followed by a brief exploration of asserting agency with reference to breaking routines that conform to the culture of research dominance. The remaining discussion explores the perspectives that have enabled the academics who were interviewed to confront research dominance where it potentially constrains their ability to engage in PD for teaching. Our findings suggest that pragmatic, social and reflexive perspectives underlie academics' rationales for engaging with PD for teaching. We speculate that these perspectives, together with structural changes at UCT, undermine the power of the dominant research discourse. In so doing, engagement with PD for teaching can increasingly be viewed as an individual choice.

\section{THEORETICAL PERSPECTIVES}

Building on Giddens' structuration theory (1984), Archer's (2003) conceptualisation of structure, culture and agency has proved a useful framework for the analysis of higher education institutions in South Africa (Quinn 2012; Leibowitz et al. 2012). The provision of PD for teaching can be seen as operating at a structural level which may enable and constrain academics' ability to transform (agency), which in part may depend on the institutional culture. Although structure, culture and agency are interlinked and operate simultaneously, the 
discussion here hones in on the cultural dimension at UCT.

Following Archer, the term 'culture' is used here to describe the ideas, beliefs, theories, values, ideologies and concepts which are manifest through discourses used by particular people at particular times. From a social realist position, discourses are part of the cultural system with enabling and constraining causal powers to affect things in the world and exert a conditioning influence on social actors (Quinn 2012, 29).

A Foucauldian (1981) orientation to the power of ideas focuses on the work of discourses in the formation of hierarchical relationships, which is useful for clarifying how a dominant research discourse positions teaching as secondary to research in academics' work. However, in this article the different ways of thinking and the ideas that shape them are understood more broadly as a range of perspectives. These beliefs and theories tell us something about how some academics are able to disrupt the way that dominant research discourses have traditionally operated, and thus assert agency.

In addition to Archer's theory that illuminated the connection between structure, culture and agency, we use Emirbayer and Mische (1998) to examine different dimensions of agency.

... agentic processes can only be understood if they are linked intrinsically to the changing temporal orientation of situated actors (Emirbayer and Mische 1998, 967).

Drawing attention to how academics' perspectives are informed by established routines (the past), current situations (the present) and long term goals (the future), helps to bring into focus the shifting institutional culture. This compliments Archer's account of agency as the pursuit of individual projects where 'what people do ... involves reference to agents' subjective and reflexive formulation of personal projects in light of objective circumstances’ (Archer 2003, 5). In theory, then, circumstances dominated by the historical, current and anticipated research dominance can be challenged through academics' undertaking projects that incorporate alternative ways of thinking about the value of PD for teaching. This imbues ideas with the capacity to bring about change to entrenched cultures.

\section{RESEARCH CONTEXT}

Concerns about promoting teaching development in the higher education sector have given rise to a growing field of academic staff development aimed at giving academics the opportunities to improve their knowledge and expertise in teaching. The analysis in this article arises out of a collaborative investigation ${ }^{1}$ conducted from 2010 to 2013 at eight South African universities representing a range of different higher educational contexts. The study explored how structural 
and cultural forces influenced individuals' engagement with professional development (PD) opportunities for teaching.

Within this spectrum of universities, UCT is positioned as a historically advantaged, English medium, urban, research-intensive university. From a structural perspective, academics at UCT have a wide range of opportunities available to them for teaching development, drawing on the extensive experience and resources of the Centre for Higher Education Development (CHED) and faculty-based educational development units. Regular seminars, workshops and courses take place and an internal Teaching and Learning Conference is organised annually. At UCT, as in most higher education institutions in South Africa, participation in these teaching development opportunities is voluntary.

The findings here are based on three sets of data collected at UCT, one of eight case studies, as part of the larger collaborative investigation. Firstly, a questionnaire was emailed to permanent academic staff. Secondly, interviews were conducted with four members of UCT's senior management, and thirdly, interviews were conducted with eleven academics selected from the 171 questionnaire respondents at UCT, to form as diverse a sample as possible with respect to discipline, gender, race, length of service at UCT and level of engagement with PD opportunities in teaching. The authors conducted a content analysis on the senior management interviews and highlighted the main points made with regards to teaching and learning at UCT, as well as key aspects related to structure, culture and agency. The authors then compared their notes and established an agreed set of codes. A similar process was followed in analysing the open-ended responses from the questionnaires and interviews conducted with academics. The coded data was analysed to identify specific instances of asserting agency and perspectives that enabled academics to justify their engagement with PD in teaching.

Ethical clearance was obtained from the lead institution, Stellenbosch University, and from each participating institution. All information identifying specific individuals and their departments was removed. Abbreviations L1 - L11 have been used here to refer to each of the academics that were interviewed. SM1 - SM4 refer to senior management interviews.

\section{FINDINGS}

\section{Cultural aspects: Dominant research discourse}

While senior management highlighted the importance of teaching, they acknowledged that the overwhelming dominance of research at UCT poses a threat for teaching development and that despite recent changes to promotion criteria that make evidence of effective teaching more 
visible, 'at the end of the day ... being a researcher is key to your success ... at UCT' (SM2). The language used by the respondents in the questionnaire and interviews largely acknowledged the dominance of the research discourse by drawing attention to a lack of choice, evidenced by pressure to publish, lack of time and having to negotiate the risks associated with investing in teaching development. (See Jawitz and Perez 2014 for a more detailed discussion of PD as a risk.)

For many academics there is no need to take teaching development seriously because it is not a cultural norm of an institution that markets itself as 'research intensive'. As such, there is evidence of the research discourse being used to justify the lack of engagement in teaching development:

... people complain about the academic rat race that requires of people to publish or perish sometimes has a bit of a detrimental effect on teaching. ... For the first two and half years I was here, I was finishing my PhD so I hadn't quite felt the pressure to publish or perish .... Now that my $\mathrm{PhD}$ has finished ... I'm wondering at what point crunch time will come where research will have to take priority over focusing on teaching. So far I've put a lot of effort into teaching which is what I guess one does when teaching new things or when you are teaching for the first time. (L4)

The above extract reveals several assumptions that demonstrate the power of the research discourse. Firstly, the expressions ‘academic rat race' and 'publish or perish' are historically entrenched phrases that have become synonymous with the stereotype of an academic. These phrases allude to the primordial importance of research over teaching at UCT, a message that is reinforced through the self-description evident on UCT's website (Jawitz and Williams 2015). Secondly, the above quote shows the speed with which the 'publish or perish' mantra is internalised. Having been at UCT for two-and-a-half years, the lecturer had been tracking his sense of how pressured he was to begin publishing. The absence of experiences of being pressured is not used as evidence of the absence of pressure, but a sign that this 'crunch time' is inevitable and has yet to come. Thirdly, the fact that, upon securing a permanent academic post, his priority was to obtain a $\mathrm{PhD}$, as opposed to a teaching qualification, indicates the extent to which the research discourse has become reified. In the absence of an academic having neither a teaching qualification nor a $\mathrm{PhD}$, the dominant research discourse at UCT positions the prioritisation of the $\mathrm{PhD}$ as natural and inevitable.

The impact of a dominant research discourse is that it positions teaching as a threat to research, where teaching takes time away from research. This was mentioned by L9, who commented that 'there's a school of thought that says that research and teaching are forever and shall be separate. Whereas I'm more of the view that the two help each other. I think they 
complement each other, you know, if you play your cards right' (L9). This reorientation to the dominant research discourse was illustrated by the way that interviewees spoke about teaching and teaching development. These interviewees were identified as asserting agency because of their refusal to accept that teaching has to be subservient to research. In doing so, they contribute to an emerging discourse through their alternative perspectives to teaching and teaching development. In the next section, we explore the explanations of this group and analyse how they are able to resist the power of the research discourse. This is not to suggest that they are unconstrained in other ways, but the dominant research discourse does not prevent them from pursuing opportunities for the PD of their teaching.

\section{Asserting agency}

The language used by those academics who have been labelled above as 'asserting agency' revealed several assumptions which influenced their engagement with the PD. In this section, we provide examples of these assumptions as instances of agency where they intersect with Emirbayer and Mische’s (1998) temporal deconstruction of agency.

The first was a major assumption that academics made about the power that they could command over the time available to them for PD in their role as teachers. For example, 'I make the time because I think it [teaching] is that important' (author's emphasis). The language revealed a rejection of past habits and routines that are historically dictated by a dominant research discourse that positions time as something that should be maximised in the pursuit of research goals. Instead, alternative routines were developed that made it possible to conceive of time as something that has to be spent both on research and teaching, and where one did not come at the expense of the other.

An example of agency in the choices academics make in response to current pressures and challenges, the practical evaluative element (Emirbayer and Mische 1998), was provided by interviewees who expressed the ability to ignore the judgements of peers for their investment in their teaching development.

I really don't care what other people do or what other people think in the department. I'm doing what I feel the job is requiring of me. I've just become more immune to what I think might be the opinion of the department (L3).

[S]ometimes people are not comfortable with wanting to upset that sort of apple cart ... I don't feel I have to toe the line (L8).

Rather than revert to ways of talking about the job as informed by the dominant research discourse, L3 and L8 prefaced their own interpretations of their roles. Their language implied 
the application of a different logic to that of their colleagues. This showed how it had become possible for some academics to 'resist and subvert the logics and practices of the established order’ (Emirbayer and Mische 1998, 1001).

As well as resisting historic routines and ways of thinking about the place of teaching compared to peers, academics assertion of agency was evident in how they talked about the future, the projective element (Emirbayer and Mische 1998).

I have no training on how to teach and it's a core part of my job ... so I feel quite motivated to try and learn more about teaching methods, how to teach large classes, how to teach in more interactive ways, so that I can provide a better service to the students essentially, and can learn as I go along and become a better teacher. (L2)

Again, an ability to teach is highlighted as 'core' to the job of being an academic. Therefore, the future projections of the role included a vision of being 'a better teacher'. Unlike the dominant research discourse that relies on academics envisaging their future selves as being more senior researchers, this academic shifted the focus to the goal of being 'a better teacher' and providing 'a better service to the students'. This way of thinking does not exclude the possibility that research can enhance teaching, but it foregrounds improvement in teaching as an ongoing process.

The ability to think differently was also evident amongst some academics who asserted agency by interpreting the institutional culture as enabling. For example, the absence of formal requirements to pursue PD opportunities for teaching was experienced as providing 'freedom'. The freedom to pursue PD for teaching was, instead, underpinned by conceptions of change, which again saw the future as a departure from the present.

We constantly need to re-evaluate what we are doing, and ... get ourselves out of our comfort zones. Challenge ourselves and be challenged by other people, by doing things differently. (L4)

Some academics' 'comfort zones' are expressed in their preference for research over teaching. In some cases, lack of interest in PD for teaching is justified, not because teaching is not important, but because it is regarded as an innate ability: 'Either you can teach or you can't, you know. And it depends very much on the example of teachers one's had oneself' (L9). Further to the creation of a 'them and us' attitude between people who can and cannot teach, was the division between older academics who make PD plans every year that are 'product orientated ... how many conference papers will you churn out?' and other academics who are interested and have a 'natural desire' to find or make connections with others (L8).

Instead of making connections with others to bring about change, the dominant research 
discourse maintains the status quo. Academics who assert agency seek out challenge and ways of doing things differently, even in the absence of any need to. By assuming that all academics 'constantly need to re-evaluate' (L8), their approach incorporates the past, present and future. The next section considers ways of thinking about their engagement in PD for teaching, grouped as three perspectives, and examines the extent to which they encroach on the power of the dominant research discourse.

\section{ALTERNATIVE PERSPECTIVES TO PROFESSIONAL DEVELOPMENT}

\section{Pragmatic perspective}

The underlying assumption of the narratives informed by a pragmatic perspective is that the purpose of PD for teaching is to find out how to do things or to solve a problem and is associated with the view of PD as 'training' to acquire a new or enhance an existing skill. The pragmatic perspective draws on rationality to position teaching development as a logical course of action given, for example, the rise of teaching with technology:

... it's not like $4 / 5$ years ago that if you want to present video material to students that you need to have a video team on your side; someone who records and sound treatment and that ... [I] realised, you're so stupid, you use your normal cyber shot, you shoot videos, you edit a little bit and you've got material that you can put online for students. So we started doing little things like that as well, just building a resource for students to go back to. (L10)

There was a sense of the value of technology in making previously arduous and time-consuming tasks easier and quicker. Not only is making a video easy, but the fact that the use of a cybershot had not occurred to her earlier made her feel stupid. By making resources available online, students can work independently. In contrast, other reasons for attending PD for teaching (such as curriculum design, theories of education, assessment strategies) are not necessarily associated with saving time and lightening the workload. Perhaps, therefore, technology is an increasingly acceptable rationale to draw on as it does not challenge the power of the research dominance discourse, but rather gives people a legitimate reason to attend PD for teaching: the lure of the technology as a labour-saving device which might free up time to spend on research. Therefore, for teaching and research enthusiasts alike, the pragmatic perspective has the potential to loosen academics from the stranglehold of the dominant research discourse without losing face.

One interviewee injected an emotional element into the justification for attending PD opportunities in teaching: '... there's no shame in not to know, but there is shame in not to go 
looking for the answers' (L7). A pragmatic perspective is evident here in the way that attending PD is born out of being honest about one's limitations and going about seeking a solution. It assumes that what one did not know before, one will come to know, having attended a workshop. In this way, PD activities can give people concrete answers and advice.

Another respondent framed constraints to engaging with PD in teaching as being driven by the time and energy likely to be involved in generating change at UCT. This was an alternative to traditional ways of thinking about PD opportunities as positioned by the dominant research discourse:

This is the most conservative university in the country and the least likely to change. 'We do things the way they were done 30 years ago because we are the best on the continent and therefore we don't need to change' is the motto of the university ... Getting something changed here is almost, nearly impossible. (L6)

Despite this interpretation of the conservative culture and slow pace of change, L6 remained committed to engaging with PD for teaching. However, he focused on changing things within his department. 'I read the literature on computer science as far as I can, and techniques for teaching ... beyond the department level I don't think there's much interaction about what professional development I get involved in’ (L6). His practical approach in consulting education journals to find out how to improve and develop his teaching was not threatened by the broader institutional culture.

\section{Social perspective}

The underlying formulation of talk informed by a social perspective indicates that PD activities are intended to provide opportunities to interact with others about teaching. It is assumed that there is something to be gained from engagement with a diverse range of people, be they novices or experts, from the same or different disciplines. The important thing is the social interaction itself, and the resulting support networks and communities.

Interviewees who drew on this perspective often recounted their own experiences of being taught or mentored. The language associated with the operation of this perspective included 'mentors' and 'communities of practice'. Both past and present social interactions were used in this perspective to interpret conversations about teaching as formative in shaping academic identity.

I worked for a fantastically charismatic person who I did my $\mathrm{PhD}$ with and he was a wonderful lecturer. There's no doubt he taught me a lot about lecturing and speaking in public. (L7) 
Similarly, for L11, her incorporation of active learning techniques had 'come through seeing good teachers' in action. These past experiences informed decision-making about the purpose and value of PD opportunities. The link with routines was made most strongly by L9, who believes 'your teaching is so much determined by what's happened before, or what's not happened'. Those who assert agency are more confident about their ability to learn from others, having already experienced this in the past themselves, either as students or academics or both.

Consequently, when thinking about the future of PD provision, some respondents sought to give a better guarantee that learning from other 'good teachers' would happen. For example, L10 advocated establishing a mentoring scheme, as her previous positive experience of learning to teach informally had taken this form. She described her experience of being mentored in a way that resembled 'gently immersing one into this environment'. Her mentor had allowed her to develop her 'own teaching style' (L10). She felt that UCT should implement a formal mentoring system between senior and junior staff. She went on to note that the current absence of mentoring not only impacts on teaching development but also contributes to a distance between junior and senior staff. This means that senior staff are less able to empathise with junior staff.

They [senior staff] don't teach these courses, it's out of their comfort zone so [senior staff] might struggle to relate to or think about [teaching.] (L10)

The above quote suggests that senior staff do not involve themselves with PD activities for teaching, such as mentoring junior staff, not because they are spending time on research, but because teaching is a source of discomfort. By focusing on the emotional aspects of teaching, it becomes easier to see why some academics see the social aspect of teaching development opportunities as valuable.

A further reason for seeking out people across the institution was to overcome a sense of social isolation within certain departments. One interviewee explained how, in her department, 'people close their door ... you can kind of spend a whole day there and not see anybody' (L1). In another example, L3 commented that 'we are not a very close department ... so there's not that much interaction'. This means that the daily experience of being an academic can potentially be a lonely and isolating one. Two lecturers used the word 'alienating' to describe how some people experience working at UCT. There was also evidence of black staff and parttime contract staff (L9) being disproportionately affected by this sense of isolation 'that's not conducive for teaching' (L1).

The value of social interaction was also spoken about in terms of building collegiality. PD 
opportunities ‘offered space to start conversations' and encouraged individuals to be interested 'in each other's work in the kind of respectful way' and helped to develop 'natural collegiality' (L8). Social engagement was also referred to in the context of teams working together within a department:

We are a close-knit team, four of us share an office so there's a good synergy among us. ... We are all on the same level ... two ... have PhD's, they are older, have a bit more life experience, so they invest in you but it's a cross pollination thing. (L10)

Social interaction outside of formal PD forums was also seen by some academics as a training opportunity, akin to the pragmatic perspective outlined previously. These might include the 'little things that you catch in the corridor or chatting to someone just off hand that you incorporate and it becomes second nature. That’s just the way you lecture now' (L3).

The subconscious nature of this type of PD was made apparent in two ways. Firstly, three out of the eleven interviewees, despite recounting experiences of PD for teaching in their interview, had categorised themselves in the questionnaire as having 'never' attending PD for teaching opportunities. When asked to explain why they had indicated that they had 'never' attended PD for teaching opportunities, they had dismissed their forms of engagement on the grounds that they had happened a long time ago, or not frequent enough to warrant indicating one of the alternative categories ('rarely', 'sometimes', 'often' or 'very often' were other multiple choice options on the questionnaire).

Secondly, some academics struggled to think of the precise source of the changes that they had made to their teaching practice:

So I have a confidence about my ability to teach that's coming from a reservoir, that I can't quantify for you that it came from this course at college that I did or that, you know, it's an accumulative experience that's about understanding that teaching is a vocation, as opposed to a job for many people, so my thinking around it is maybe different from others (L8).

Social interaction may raise the status of teaching through informal conversations and function as a form of training when teaching ideas are shared and incorporated by colleagues. However, if this type of PD does not constitute a dedicated time slot or session, then the value of social interaction is unconscious. This was evident in the reflection of one interviewee on the New Academic Practitioner Programme (NAPP):

I'm not a believer that everybody has something to contribute. I think some people should listen more than they talk. Unfortunately, you know, the prevailing notion in society is that everybody should talk an equal amount. (L6) 
The way that social interaction is valued varies greatly and the social perspective is not a feature of the narrative of all respondents who are described as asserting agency. It is also less easy to articulate, in terms of what individuals gained, compared to the pragmatic perspective for attending PD activities.

\section{REFLEXIVE PERSPECTIVE}

Closely linked to the value of social interaction, for some academics, PD is more tied to a thought-process than resulting in a concrete outcome. This third perspective views PD activities as promoting reflexivity, in a similar way to that carried out by qualitative researchers. A reflexive approach incorporates the process of introspection, reflection and critique (Rose 1997) in the examination of assumptions and preconceptions and how these affect the choices we make (Hsiung 2010).

Participation in PD activities was described as helping to get one 'thinking about and talking about [teaching]' (L3). This prompt to think was credited with having 'helped all of us get our heads around how we can teach effectively' (L4). The heart of this view is an individual quest to improve practice by exploring ideas, implementing and reflecting as part of a continuous improvement cycle. This reflective practice promoted a growth in confidence through the process of experiential learning.

While acknowledging the value of reflecting, L11 expressed dissatisfaction with the trialand-error nature of the process and its impact on her practice:

[It's] me making it up as I go along. I've done a little bit of reading and been to a few workshops, but it is very much building on experience and seeing what works and what doesn't work, which I actually think is a weakness of the way we teach at the university. (L11)

The above text is part of a response to a question about why she had categorised herself as never having attended PD opportunities, despite having given several examples of her engagement with PD for teaching in the interview. The ongoing nature of reflecting and modifying was experienced as a deficiency. She laments that 'every year I sit down and look at everything that's available and I make ticks and I'm going to try and do it, and I have no time'. For her, it seems that going to one workshop does not constitute taking up PD opportunities, because attendance should be regular and ongoing.

Her reference to time above is not directly linked to the dominant research discourse. Instead she referred to the 'continuous stream of people coming through my office making demands on me' that uses up time that could otherwise be spent on PD for teaching. There seems to be a tacit link between time, routine and something being worthwhile. For her it is 
important that engagement with PD activities be thoughtful, systematic and ongoing rather than ad hoc and spontaneous.

The value of reflexivity is that it fosters a critical and evaluative orientation to thinking about teaching. However, even where this is evident, if it is not exercised with a degree of formality or regularity then, even among lecturers who assert agency, the process is devalued. For some academics, asserting agency refers to those who attend training and seek out interaction or reflection. If this is not performed with the same diligence as that associated with research, then, in their own minds, these opportunities are rendered peripheral. This lack of recognition within themselves means they might not acknowledge that PD for teaching has taken place, as happened with several respondents in this study.

The opinion that PD opportunities in teaching should be formal and structured to be of value was not held by all. One interviewee, a Head of Department said 'I'm aware of my colleagues asking others to attend their own lectures to give them feedback. So [while] these things may be happening informally, ... all of these processes add to the development of the teacher' (L10). Although recognised as PD for teaching, the labelling of peer observation as 'informal' could suggest that the pragmatic function of discrete workshops might remain more consciously valued than that of the social or reflexive perspectives.

\section{CONCLUSION}

The ability of academics in higher education institutions to consciously pursue avenues to improve their teaching is dependent on their daily experience of working at an institution. Academics may have fundamentally different experiences at this level. This is evident in the emergence of clusters of colleagues and departments that allow for the possibility of academics spending time developing their teaching, while just down the corridor there are spaces where the supremacy of research remains entrenched and excludes the consideration of time spent on such activities.

Within the context of research intensive institutions such as UCT, despite a dominant research discourse that interferes with the way academics engage with PD opportunities for teaching, a set of academics have been able to overcome these constraints. Their practice is characterised by an assertion of agency, driven by strong self-motivation to improve their teaching and successfully facilitate learning amongst their students. This assertion of agency was reflected in four areas of their engagement with the PD space, namely, making time, applying new learnings to their disciplinary contexts, re-interpreting a perceived institutional disregard for teaching as a freedom to engage, and building support networks and communities. 
Evidence of their agency spanned across all three temporal elements identified by Emirbayer and Mische (1998) namely, the iterational element based on past practices, the practical evaluative element involving making choices based on current dilemmas and challenges and the projective element reflecting plans and aspirations.

The stories of the interviewees who assert agency in this way were found to reflect an adoption of a range of perspectives which we have labelled pragmatic, social and reflexive. These perspectives help us to understand the basis for justifying spending time in PD activities for teaching and how they make choices to maximise the value they are able to extract from these PD opportunities.

The evidence presented here of academics in this context increasingly taking charge and asserting agency in developing professionally as teachers despite constraints, points to an emerging culture in which not investing in PD for teaching is increasingly exposed as a choice. Historically, most academics at research-intensive institutions have been protected by a research-dominant discourse that justifies the neglect of teaching. This study brings into question the extent to which academics at research-intensive institutions such as UCT can continue to avoid developing their teaching. The emergence of an alternative teaching discourse by academics asserting agency serves to undermine the power of the dominant research discourse and the subsequent safety of academics who use it to justify not spending time on their PD in teaching.

\section{NOTE}

1 National Research Foundation (NRF) funded project entitled Structure, Culture and Agency: grant number 74003.

\section{REFERENCES}

Archer, M. 2003. Structure, agency and the internal conversation. Cambridge: Cambridge University Press.

Chalmers, D. 2011. Progress and challenges to the recognition and reward of the scholarship of teaching in higher education. Higher Education Research \& Development 30(1): 25-38. doi:10.1080/07294360.2011.536970.

Colbeck, C. L. 1998. Merging in a seamless blend: How faculty integrate teaching and research. Journal of Higher Education 69(6): 647-671. doi:10.2307/2649212.

Emirbayer, M. and A. Mische. 1998. What is Agency? American Journal of Sociology 103(1): 9621023.

Foucault, M. 1981. The order of discourse. Untying the text, ed. R. Young. London: Routledge and Kegan Ltd.

Giddens, A. 1984. The constitution of society: Outline of the theory of structuration. UK: Polity Press. Hsiung, Ping-Chun. 2010. 'Lives and legacies: A guide to qualitative interviewing.' http://www.utsc. 
utoronto.ca/ pchsiung/LAL/reflexivity (accessed 2 August 2015).

Jawitz, J. and K. Williams. 2015. Presence and absence: Looking for teaching and teaching development in the website of a 'research-led' South African university. Critical Studies in Teaching and Learning (CriSTaL) 3(1): 44-60. doi:10.14426/cristal.v3i1.41.

Jawitz, J. and T. Perez. 2014. 'Learning to teach at UCT: A risky business?' University of the Free State, Bloemfontein, HELTASA, 18-21 November 2014. http://heltasa.org.za/wp-content/ uploads/2015/01/HELTASA-Programme.pdf.

Jawitz, J. and T. Perez. 2015. Investing in teaching development: Navigating risk in a research intensive institution. International Journal of Academic Development. 21(3): 194-205. doi:10.1080/1360144X. 2015.1081852

Kreber, C. 2000. How university teaching award winners conceptualise academic work: Some further thoughts on the meaning of scholarship. Teaching in Higher Education 5(1): 61-78. doi:10.1080/ 135625100114966.

Leibowitz, B. 2014. Conducive environments for the promotion of quality teaching in higher education in South Africa. Critical Studies in Teaching and Learning (CriSTaL) 2(1): 49-73.

Leibowitz, B., V. Bozalek, S. van Schalkwyk and C. Winberg. 2015. Institutional context matters: The professional development of academics as teachers in South African higher education. Higher Education 69(2): 315-330. doi:10.1007/s10734-014-9777-2.

Leibowitz, B., S. van Schalkwyk, J. Ruiters, J. Farmer and H. Adendorff. 2012. 'It's been a wonderful life': Accounts of the interplay between structure and agency by 'good' university teachers. Higher Education 63(3): 353-365. doi:10.1007/s10734-011-9445-8.

Leisyte, L., J. Enders and H. De Boer. 2009. The balance between teaching and research in Dutch and English universities in the context of university governance reforms. Higher Education 58(5): 619-635. doi:10.1007/s10734-009-9213-1.

Quinn, L. 2012. Enabling and constraining conditions for academic staff development. In Re-imaging academic staff development: Spaces for disruption, ed. L. Quinn, 27-50. Stellenbosch: SUN MeDIA.

Rose, G. 1997. Situating knowledges: Positionality, reflexivities and other tactics. Progress in Human Geography 21(3): 305-320.

Skelton, A. 2012. Teacher identities in a research-led institution: In the ascendancy or on the retreat? British Education Research Journal 38(1): 23-39. doi:10.1080/01411926.2010.523454.

Van Schalkwyk, S., B. Leibowitz, N. Herman and J. Farmer. 2015. Reflections on professional learning: Choices, context and culture. Studies in Educational Evaluation. http://www.research gate.net/publication/274264278_Reflections_on_professional_learning_Choices_context_and _culture. 